\title{
A verdade do coração: circulação de livros e retórica sentimental no Diário do Rio de Janeiro
}

\author{
André Cabral de Almeida Cardoso ${ }^{1}$
}

\begin{abstract}
Resumo: Levando em consideração a importância da imprensa periódica na disseminação da literatura ao longo do século XIX, este artigo examina textos de diversos tipos publicados no jornal Diário do Rio de Janeiro entre os anos de 1830 e 1860 , a fim de rastrear a maneira como as obras literárias eram divulgadas e lidas nesse período, tomando como referencial os trabalhos de Abreu $(2013 ; 2014$; 2016a; 2016b), Mançano (2010) e Augusti (2006) sobre a circulação de livros no Brasil oitocentista. Parte-se de uma análise dos anúncios de livros à venda colocados no jornal, que oferecem indicações sobre aquilo que se julgava ser de interesse do leitor, para em seguida se investigar resenhas, biografias de escritores e artigos de opinião também publicados no periódico, com o objetivo de mapear a maneira como essas obras eram recebidas. Dada a forte presença de uma retórica sentimental nesses textos, busca-se mostrar de que modo essa retórica revela, ou mesmo ajuda a moldar, determinadas atitudes relacionadas às funções da literatura, às condições de sua recepção e à sua relação com o pensamento.
\end{abstract}

Palavras-chave: Sentimentalismo. Circulação de livros no século XIX. Periódicos. Romance. Crítica.

\section{Introdução}

Em 16 de fevereiro de 1827, o Diário do Rio de Janeiro trazia a seguinte chamada no anúncio dos livros à venda publicado naquele dia pela loja de papel Coutinho \& Agra, localizada na R. do Ouvidor, n. 113: “Atala, ou os amores de 2 Selvagens no dezerto: novella senlimental [sic], e mui interessante, traduzida do original de Mr. de Chateaubriand, e maior escriptor que a França actualmente possue" (DRJ, 16/02/1827, p. 1). ${ }^{2}$ Não se tratava de uma novidade: o romance de Chateaubriand já havia sido anunciado pelo menos oito vezes no Diário entre 1825 e 1826. Entretanto, essa é a primeira vez em que o nome do autor é mencionado, juntamente com o gênero da obra. É possível que o acréscimo dessas informações se deva a uma mudança dos anunciantes, já que na divulgação anterior do livro aparecia um outro endereço em que ele poderia ser adquirido. De qualquer forma, os termos em que o anúncio é formulado nos fornecem algumas indicações interessantes a respeito de como esse romance

\footnotetext{
${ }^{1}$ Doutor em Literatura Comparada pelo Departamento de Literatura Comparada da New York University (2009). Professor de Literaturas de Língua Inglesa, Departamento de Letras Estrangeiras Modernas (UFF). Brasil. E-mail: andrecac@id.uff.br Orcid: http://orcid.org/0000-0002-5596-2157

${ }^{2}$ Optei por manter a grafia original em todas as citações de textos publicados no Diário do Rio de Janeiro.
} 


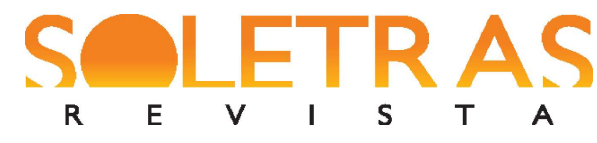

N. 40 - 2020.2 - ANDRÉ CABRAL DE ALMEIDA CARDOSO

estava sendo promovido. Primeiro, uma vez que os anúncios de livros no Diário do Rio de Janeiro, assim como em outros periódicos da época, costumavam se limitar a uma lista de títulos sem nenhum outro dado além do número de volumes de cada obra e de seu preço (e muitas vezes sequer este era informado), a quantidade de texto empregado neste caso já mostra que se pretendia dar um destaque especial a Atala e que as informações fornecidas seriam de especial interesse para o leitor. Depois, há uma clara tentativa de capitalizar sobre o prestígio de Chateaubriand ao apresentá-lo como o maior escritor vivo da França. Finalmente, tem-se a preocupação de assegurar não só que o romance é "mui interessante", mas também de que se trata de uma narrativa sentimental; deduz-se não só que o gênero seria familiar, mas também um atrativo especial para o leitor, além de ser digno da pena, como já dito, do "maior escriptor que a França actualmente possue".

O uso dessa expressão hiperbólica no anúncio dá ao romance sentimental uma posição respeitável em um dos mais importantes centros de produção e difusão de literatura no século XIX (ABREU, 2016a, p. 11). De fato, a literatura sentimental gozou de enorme prestígio desde meados do século XVIII até as primeiras décadas do século XIX, mantendo-se extremamente popular e angariando também, muitas vezes, o respeito da crítica. ${ }^{3}$ Mesmo depois de seu apogeu, é possível perceber a presença de elementos oriundos da estética sentimental em romances e outras obras literárias publicadas ao longo de todo o século XIX - ou seja, longe de ser suplantada com o surgimento dos primeiros romances realistas, por exemplo, essa estética manteve-se bastante produtiva. Como Márcia Abreu (2013, p. 34-35; 2014, p. 43; 2016a, p. 27) observa, não só certas obras se conservaram no gosto do público durante muito tempo, como também as maneiras de compreendê-las e avaliá-las permaneceram relativamente estáveis ao longo de boa parte do século XIX, não sendo possível analisar esses textos simplesmente através da sucessão de "escolas" literárias, já que a convivência de diferentes estilos literários era mais frequente do que a ruptura, ainda que essa convivência pudesse também envolver conflitos. No caso específico da estética sentimental, muitos de seus temas e recursos formais continuaram a ser apropriados e postos em ação em textos de natureza diversa, mesmo aqueles que não se enquadravam na literatura sentimental stricto sensu. Talvez se possa dizer que o sentimentalismo, assim como o gótico - vertente à qual a literatura sentimental está ligada,

\footnotetext{
${ }^{3}$ Ver o trabalho de Margaret Cohen (1999, p. 6, 10), que considera o romance sentimental o modo dominante do romance ao longo desse período. Para a formação de uma cultura sentimental na Grã-Bretanha do século XVIII, ver Barker-Benfield (1996).
} 


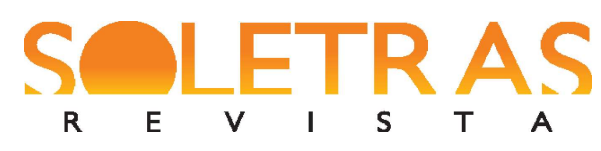

N. 40 - 2020.2 - ANDRÉ CABRAL DE ALMEIDA CARDOSO

principalmente através da obra de Ann Radcliffe e seus seguidores -, configura-se como um modo discursivo que permeia diferentes gêneros durante o século XIX. ${ }^{4}$

Como se pode perceber através da leitura dos anúncios de livros, crônicas, comentários e textos de natureza diversa publicados no Diário do Rio de Janeiro durante boa parte do século XIX, a ficção sentimental não só permaneceu popular, como gerou uma série de expectativas que influenciou a maneira como a literatura era encarada. Um exame desses textos pode fornecer pistas importantes sobre alguns dos protocolos de leitura e concepções a respeito dos efeitos da literatura que continuaram vigentes ao longo desse período. A escolha do Diário do Rio de Janeiro como objeto desta análise se deu pelo fato de que este foi um periódico de grande circulação, voltado para um público amplo e não especializado, ao mesmo tempo em que demonstrava uma preocupação com a literatura e a cultura em geral. Parte-se do princípio, assim, de que o material publicado no Diário teria uma grande ressonância com o seu público, refletindo - ou ajudando a formar - atitudes correntes sobre a produção e recepção de obras literárias. Irei me concentrar no período que se estende de 1830 a 1860 e corresponde ao amadurecimento do romance nacional, abrangendo a época em que José de Alencar foi redatorchefe do Diário - onde, aliás, publicou pela primeira vez, em formato de folhetim, Cinco minutos e $O$ Guarani. Partirei de uma análise dos anúncios de livros divulgados no jornal, dando especial atenção àqueles que dão destaque a elementos que seriam do interesse do leitor, ao mesmo tempo em que já guiam a maneira como se esperava que as obras fossem lidas. Em seguida, examinarei até que ponto os termos nos quais os livros são anunciados encontram um reflexo em comentários críticos, textos sobre literatura e biografias de alguns autores, também publicados no jornal, buscando mostrar como uma retórica sentimental é articulada nesses discursos.

\section{Livros à venda: os romances sentimentais nos anúncios do Diário do Rio de Janeiro}

Em geral, os anúncios de livros publicados no Diário do Rio de Janeiro surgiam na forma de listas sob o cabeçalho "Livros à venda", divulgadas por diferentes livreiros. Essas listas, que apareciam sempre de forma mais ou menos intermitente, eram muito frequentes até

\footnotetext{
${ }^{4}$ Para a caracterização do gótico como modo de escrita e não apenas como um gênero historicamente delimitado, ver Botting (2005, p. 9) 


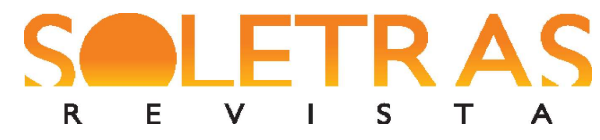

N. 40 - 2020.2 - ANDRÉ CABRAL DE ALMEIDA CARDOSO

meados da década de 1850, quando assumem um novo formato nos anúncios publicados pela livraria Garnier. No final da década de 1840, porém, elas se tornam mais curtas, focando em livros técnicos ou religiosos - curiosamente, é nessa mesma época que o Diário começa a publicar, de forma mais sistemática, resenhas, crítica teatral, pequenas biografias de escritores e artigos relacionados ao mundo das letras, voltados principalmente para a poesia, a história e a filosofia. Antes disso, os anúncios colocados no jornal listavam uma grande quantidade de romances, muitas vezes misturados com obras de outra natureza, mas em geral agrupados em conjunto. A ordenação dos livros nessas listagens parece aleatória, não havendo uma preocupação de organizá-los em termos de gêneros narrativos, prestígio cultural, data de publicação ou nacionalidade. As informações fornecidas são mínimas, limitando-se, via de regra, ao título do romance, número de volumes que este contém e seu preço, o que muitas vezes torna difícil a sua identificação, ainda mais porque trata-se geralmente de obras não canônicas que acabaram caindo em esquecimento. ${ }^{5}$ Isso confirma a constatação, já presente em outros estudos, ${ }^{6}$ de que a maioria das obras em circulação no Brasil do século XIX e que gozavam de popularidade junto ao público acabaram não sendo incluídas nas histórias literárias. No entanto, como observa Márcia Abreu (2014, p. 41-42), é preciso levar em consideração esses textos, já que eles faziam parte do contexto mais amplo com que todo escritor dialogava e deixaram suas marcas mesmo naqueles títulos que vieram a ser considerados canônicos.

Apesar da dificuldade de identificar com precisão boa parte das obras listadas nos anúncios de livros, é possível encontrar vários romances sentimentais entre elas, o que mostra que o gênero teve uma presença significativa no mercado livreiro ao longo do século XIX. Pinçando como exemplo alguns títulos de identificação mais segura citados entre 1830 e 1860 , temos o seguinte resultado:

Tabela 1 - Romances sentimentais anunciados no Diário do Rio de Janeiro entre 1830 e 1860 :

\begin{tabular}{|l|c|c|c|}
\hline \multicolumn{1}{|c|}{ Título } & $\begin{array}{c}\text { No. de } \\
\text { ocorrências }\end{array}$ & $\mathbf{1}^{\mathbf{a}}$ menção & Última menção \\
\hline $\begin{array}{l}\text { Adélia de Senange } \\
\text { (Adelaïde de Souza) }\end{array}$ & 14 & $24 / 03 / 1831$ & $04 / 12 / 1854$ \\
\hline $\begin{array}{l}\text { Carlos e Maria } \\
\text { (Adelaïde de Souza) }\end{array}$ & 18 & $02 / 04 / 1830$ & $22 / 06 / 1855$ \\
\hline
\end{tabular}

\footnotetext{
${ }^{5}$ A dificuldade de identificar esses romances, assim como sua complexa circulação até chegarem ao Brasil, é ilustrada por Sandra Vasconcelos (2016) em sua discussão sobre a tradução de Persuasion, de Jane Austen.

${ }^{6}$ Ver, por exemplo, Mançano (2010) e Abreu (2013; 2016a).
} 


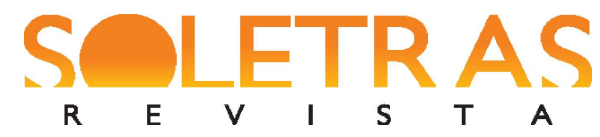

N. 40 - 2020.2 - ANDRÉ CABRAL DE ALMEIDA CARDOSO

\begin{tabular}{|c|c|c|c|}
\hline $\begin{array}{l}\text { Elizabeth, ou os } \\
\text { desterrados da Sibéria } \\
\text { (Sophie Cottin) }\end{array}$ & 21 & $18 / 01 / 1830$ & $28 / 12 / 1854$ \\
\hline $\begin{array}{l}\text { Clara d'Alba } \\
\text { (Sophie Cottin) }\end{array}$ & 27 & $18 / 01 / 1830$ & $18 / 07 / 1855$ \\
\hline $\begin{array}{l}\text { Ourika } \\
\text { (Claire de Duras) }\end{array}$ & 32 & $15 / 02 / 1830$ & $13 / 05 / 1855$ \\
\hline $\begin{array}{l}\text { Cartas de uma peruviana } \\
\text { (Françoise de Graffigny) }\end{array}$ & 42 & $06 / 05 / 1830$ & $20 / 06 / 1855$ \\
\hline $\begin{array}{l}\text { Paulo e Virgínia } \\
\text { (Bernardin de Saint-Pierre) }\end{array}$ & 46 & $01 / 02 / 1831$ & $04 / 10 / 1857$ \\
\hline
\end{tabular}

Mais interessante do que o número de vezes que esses livros são mencionados é o intervalo de tempo em que isso acontece: todos eles são anunciados praticamente ao longo de todo o período entre 1830 e 1860. Mesmo Adélia de Senange, que aparece com uma frequência bem menor, é listado durante quase 25 anos. Não só esses livros permaneciam muito tempo em circulação, como também eram de publicação antiga, ${ }^{9}$ o que, mais uma vez, corrobora a observação de Márcia Abreu (2014, p. 40-41) e Regiane Mançano (2010, p. 90-92) de que o gosto do público permaneceu praticamente estável na primeira metade do século XIX. Essa situação começou a mudar com o surgimento dos folhetins no Brasil, que tornou populares obras e autores mais recentes (ABREU, 2014, p. 41). Entretanto, nos anúncios publicados pela Garnier em 1854 e 1855, ao lado de nomes como Sue e Dumas, que deviam sua fama ao folhetim, aparecem ainda, em meio à lista de romances diversos, os mesmos títulos divulgados nas primeiras décadas do século, o que indica que eles não foram de modo algum abandonados.

Se os dados sobre os livros anunciados no Diário do Rio de Janeiro apontam para a presença significativa de romances sentimentais entre as obras em circulação, a menção a nomes de autores é outra indicação importante da receptividade que o gênero encontrava. Como já indicado, não é frequente as listagens incluírem a autoria dos livros que divulgavam; quando

\footnotetext{
${ }^{7}$ Há várias ocorrências de apenas Elizabeth ou Isabel, uma variante de Elizabeth que aparece com frequência nesse título; como nesses casos não há como ter certeza de que se trata de fato do romance de Cottin, foram contabilizadas apenas as ocorrências em que o subtítulo é mencionado.

${ }^{8}$ Márcia Abreu (2016b, p. 378) inclui Cartas de uma peruviana e Paulo e Virgínia entre os livros de maior sucesso em Portugal e no Brasil no início do século XIX. Os dois também são citados por Regiane Mançano (2010, p. 7071) entre os livros anunciados por mais tempo em sua pesquisa sobre a propaganda de livros no Correio Brasiliense, na Gazeta do Rio de Janeiro e no Jornal do Commercio.

${ }^{9}$ Para ficarmos apenas nos exemplos citados, somente Ourika foi publicado numa data relativamente próxima ao início do período estudado, 1823. Elizabeth, Carlos e Maria e Paulo e Virgínia são da primeira década do século. Já Clara d'Alba é de 1799, enquanto Adélia de Senange é de 1794. Cartas de uma peruviana é ainda mais antigo, tendo sido publicado originalmente em 1747.
} 


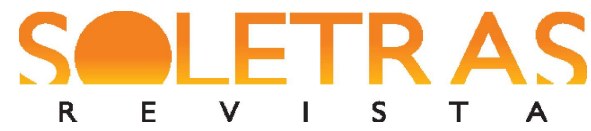

N. 40 - 2020.2 - ANDRÉ CABRAL DE ALMEIDA CARDOSO

isso ocorre, é de concluir que o autor em questão gozasse de algum prestígio ou tivesse certa fama junto ao público. Para além do próprio Chateaubriand, nomeado no anúncio citado no início deste artigo, ou Bernardin de Saint-Pierre, é comum encontrar referências explícitas a outros autores ligados à tradição sentimental, como Mme. Duras, Mme. Cottin, Mme. Tencin ou Mme. Montolieu, que teve suas obras completas anunciadas diversas vezes nas páginas do Diário. Os anúncios da Garnier, publicados na década de 1850, ainda incluíam Cottin e Tencin entre os autores cujos nomes apareciam em destaque, impressos num tipo maior e em negrito, geralmente entre as obras recém-chegadas de Paris.

Além disso, há o caso das referências cruzadas, quando se indica que um determinado romance é da mesma autoria de outra obra já conhecida pelo público, como no caso de um anúncio publicado pela Garnier em 16 de novembro de 1854, em que a qualidade de Anna Grenwill é assegurada pelo fato de o romance ser do mesmo autor do sentimental Celestina, ou os esposos sem o serem, de Bellin de La Liborlière ( $D R J, 16 / 11 / 1854$, p. 3). Vale notar, também, que vários dos romances já traziam no próprio título um claro apelo sentimental, como era o caso de Recreações do homem sensível, Os dois infelizes, Amelia ou os desgraçados efeitos da extrema sensibilidade, Maria, ou a menina desgraçada, Irma ou as desgraças de uma jovem órfã Emma, ou a filha do desgosto, A aflição confortada e História da virtuosa e infeliz Clara, sendo que o último possivelmente é Clarissa, de Samuel Richardson, uma das obras fundadoras da literatura sentimental e citada em um anúncio de 17 de fevereiro de 1834 como História da virtuosa infeliz Clara Harlowe (DRJ, 17/02/1834, p. 2). ${ }^{10}$

Esses são títulos que evocam diretamente a sensibilidade e prometem o efeito central da literatura sentimental, que é comover e despertar a compaixão do leitor. O fato de que esses eram elementos atraentes para o público fica evidente na linguagem empregada em algumas das raras ocasiões em que se faz uma apresentação mais elaborada do livro divulgado, quando se coloca em ação uma forte retórica sentimental. É o caso, por exemplo, do anúncio de $A$ moura encantada, onde, após se garantir que o romance é não só "mui digno de ser mais de uma vez lido, mas até das honras de esclarecida crítica", se lê o seguinte parágrafo:

A moura encantada é uma d'essas melancolicas harmonias, ou um desses patheticos accordos que [ilegível] amor tira d'alma, ahi vibrando a magica

\footnotetext{
${ }^{10}$ Harlowe é o sobrenome da heroína de Richardson.
} 
corda sentimental languidamente afinada por uma sympathia extremada nas delicias de um amor tão puro, como um coração de virgem, que ama só porque ama. (DRJ, 11/09/1845, p. 2)

O extravagante discurso sentimental desse trecho deixa antever o tipo de linguagem e atmosfera que o leitor encontraria na narrativa e que, apresentadas de forma positiva, servem como justificativa da alegada qualidade do romance. Ao mesmo tempo, o anúncio oferece a chave que orienta a maneira como a narrativa deve ser lida, partindo-se do princípio de que o coração do leitor também irá vibrar com a "magica corda sentimental". Como é comum na literatura sentimental, o mecanismo da simpatia, na acepção de capacidade de sentir com o outro, é representado no texto ao mesmo tempo em que se espera que ele seja reproduzido pelo leitor. A evocação de "um amor tão puro, como um coração de virgem" não só tranquiliza o público em relação à probidade moral da obra, ${ }^{11}$ como também associa a moral ao sentimento, colocado como elemento de fruição estética e, portanto, como objeto de desejo para o leitor. Depois desses arroubos sentimentais, talvez seja surpreendente ver A moura encantada ser descrito, no parágrafo seguinte, como um romance histórico focado no estabelecimento de Portugal como nação durante a luta contra os mouros. Entretanto, essas duas tendências - a entrega a enleios sentimentais e a reconstituição da realidade histórica - não são apresentadas como contraditórias, mas como perfeitamente compatíveis, até porque aquilo que a narrativa realmente tentaria resgatar é o espírito do povo português em seu momento heroico, e não tanto os pormenores de um relato mais propriamente historiográfico.

Outro anúncio que parece tentar conciliar impulsos contraditórios é o do romance Divina pastora, de José Antonio do Valle:

Acaba de sahir á luz esta interessante novella brasileira, onde se lê a discripção dos habitantes e costumes dos povos do Rio Grande do Sul e de muitas scenas domesticas em que a virtude apparece sempre triumphante, e o vício açoutado pelo castigo de Deus; assim como muitas [sic] episodios da história brasileira e muitas melodiosas poesias inspiradas pelo ceo sereno e puro das terras do Brasil [...]. (DRJ, 29/03/1848, p. 3)

\footnotetext{
${ }^{11}$ Sobre a moralidade como critério central no julgamento crítico da ficção no século XIX, ver Abreu (2013, p. 28,$35 ; 2014$, p. 42; 2016b, p. 371) e Augusti (2006, p. 50-55). Quanto à preocupação dos anunciantes de apontar para a moralidade dos livros que divulgavam, refletindo os mesmos critérios adotados pela crítica, ver Mançano (2010, p. 123-124, 141-142).
} 
Aqui, parte-se da tentativa de fazer um registro quase etnográfico da província do Rio Grande do Sul para logo se enveredar mais uma vez pela defesa de princípios morais, desta vez claramente associados à religião. Esse movimento é intermediado pela inclusão das "scenas domesticas", que estão ligadas ao campo do registro de costumes, mas já trazem em si uma forte carga de valores relacionados à família e ao apreço dado à intimidade, principalmente dentro da tradição sentimental, em que a domesticidade era ao mesmo tempo símbolo e ponto irradiador da moral burguesa. A busca da virtude ou sua afirmação, aliás, é um tema caro à literatura sentimental, muitas vezes marcado já no título da obra, como no caso de Carolina de Lichtfield, ou o triunfo da virtude, de Isabelle de Montolieu, ou de Pamela ou a virtude recompensada, de Samuel Richardson, ambos anunciados diversas vezes nas páginas do Diário do Rio de Janeiro. Pamela, aliás, é um exemplo típico do conflito central do romance sentimental, que Richardson levaria a um ponto ainda mais extremado em Clarissa: a tentativa por parte da protagonista de defender sua virtude diante das ameaças colocadas pelo mundo e, ao fazer isso, reafirmar o seu valor. ${ }^{12}$ Triunfante ou não, a virtude é colocada em total oposição à influência corruptora da sociedade. No anúncio de Divina pastora, a ameaça de conflitos sociais surge no retorno a um registro mais realista, através da menção a "episódios da história brasileira", mas esta é prontamente evitada quando o texto se volta mais uma vez para a linguagem do sentimento, representada pela promessa de fruição de "melodiosas poesias" que são o fruto da natureza serena, e portanto pacífica, do Brasil. O recurso à cor local, portanto, é valorizado não só como notação do real, mas principalmente como meio de integração a um vago espírito brasileiro, ligado à sua natureza e à harmonia de sua domesticidade, via a ativação de uma espécie de empatia.

Um recurso semelhante de identificação é empregado em outros dois anúncios publicados no Diário do Rio de Janeiro:

\footnotetext{
12 Para Margaret Cohen (1999, p. 60-62), o enredo do romance sentimental se estrutura em torno de um teste constante da virtude de seu protagonista e tem um caráter fundamentalmente ético, estando calcado no conflito entre dois princípios igualmente válidos: o dever de manter o bem comum, representado pela razão e as convenções morais da sociedade, e o direito à liberdade individual, associado à natureza, à privacidade, ao sentimento, à escolha e ao amor erótico (p. 34-40). Quanto ao tema da virtude ameaçada e suas implicações sociais e ideológicas, ver Brissenden (1974).
} 
Vida do jovem Luiz XVII, filho do infeliz rei da França Luiz XVI: a vida d'aquelle infeliz principe, que foi victima dos calamitozos acontecimentos da revolução franceza, deve interessar a todos os coraçoes sensiveis [...]. (DRJ, $12 / 09 / 1842$, p. 2)

Historia da Reforma Protestante, em Inglaterra, e Irlanda, fazendo vêr, que este aconticimento abateu, e empobreceu a maior parte dos habitantes destes Paízes, em huma collecção de cartas, dedicadas a todos os Inglezes justos, e sensiveis. (DRJ, 24/08/1830, p. 1)

Nos dois exemplos, faz-se um apelo direto à compaixão do leitor, focado, no caso do primeiro, no "infeliz principe" Luiz XVII, convertido assim em um eco da "infeliz Clara Harlowe" - o que, aliás, desestabiliza o gênero a que pertenceria o livro anunciado, que poderia ser tanto um relato histórico quanto um romance. Já no caso do segundo, é toda a população da Inglaterra e da Irlanda que se torna objeto de pena; o interessante é que também se faz referência a uma convenção formal muito comum dos romances sentimentais, que frequentemente se estruturavam como romances epistolares - as cartas eram tidas como um meio de expressar de forma direta e imediata os sentimentos. O uso da palavra "sensíveis", nos dois anúncios, serve mais uma vez como um guia para a leitura: é através da sensibilidade que se deve abordar o conteúdo das duas obras. A compaixão não seria um efeito secundário desses livros, mas a condição para a construção de seu sentido, uma vez que eles se voltam para os homens sensíveis. A sensibilidade se torna, assim, uma marca de pertencimento a um grupo, o dos homens sensíveis, aqueles a quem as obras irão interessar e que serão capazes de compreendêlas. Trata-se, é claro, de uma estratégia de convencimento não só para que os leitores a que os anúncios se dirigem comprem os títulos divulgados, mas também para que concordem com posições políticas e religiosas que os dois textos defendem tacitamente: a oposição aos males da Revolução Francesa e da Reforma protestante, que comoveriam o espírito de qualquer um dotado de sensibilidade. O emparelhamento de "justos, e sensíveis”, no segundo anúncio, não é casual, pois implica que julgar negativamente o protestantismo na Inglaterra e na Irlanda é um resultado direto da sensibilização do leitor.

A articulação da sensibilidade como estratégia de convencimento se dá de forma ainda mais radical no anúncio do livro Poesias oferecidas às senhoras rio-grandenses por sua patrícia D. Delfina Benigna da Cunha: 


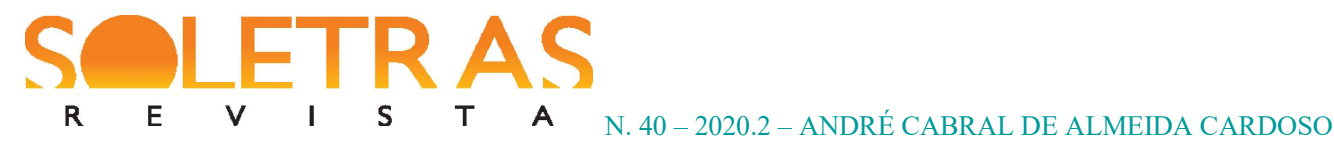

Este opusculo he digno de atenção de todos os leitores, não só pelo seu estilo e beleza poetica que enserra, mas tambem por acrescer a circunstancia de ter sua autora cegado na idade de 2 annos, não tendo nunca outros mestres se não a natureza, e hum coração sensivel. He de esperar que as Sras. fluminenses acolhão favoravelmente suas produções, pois a sua contemplação tem jus incontestavel, sendo Brasileira illustre nas letras, e dezaventurada. (DRJ, $19 / 06 / 1835$, p. 2)

Os formidáveis atributos de D. Delfina Benigna, que tornam seu mérito como poetisa inquestionável, incluem sua nacionalidade, sua ilustração nas letras e sobretudo o fato de ela ser digna de pena. Não se trata apenas de adquirir o seu livro de poemas num ato de caridade ainda que sem dúvida também seja isso o que está em jogo aqui -, pois sua condição de desaventurada sofredora deve ser levada a sério como garantia da qualidade de sua produção poética. Na tradição sentimental, há poucas coisas que poderiam recomendar melhor um autor do que não ter tido nenhum outro mestre além da natureza e um coração sensível. Essas são marcas de excelência que conferem aos poemas de D. Delfina um ar de autenticidade, ao mesmo tempo em que estes seriam capazes de desvelar os pensamentos mais delicados. Além disso, a situação infeliz da autora é uma garantia de que sua obra despertará o grau adequado de enternecimento, numa avaliação que vê a poesia como expressão do sentimento.

O que todos esses anúncios revelam é que a evocação de valores da literatura sentimental não só era um fator atrativo para os leitores, mas também que esses valores serviam de base para uma série de atitudes em relação ao texto, funcionando como medida para a capacidade de leitura e a qualidade da própria obra. Eles eram a porta de entrada para os livros apresentados e forneciam os meios através dos quais eles deveriam ser apreendidos. Resta examinar até que ponto essas atitudes se refletiam nos comentários críticos a respeito de literatura.

\section{Um olhar sensível: anotações dispersas sobre a literatura}

Em uma crônica sobre a produção dramática nacional, publicada no Diário do Rio de Janeiro em 24 de janeiro de 1853, lamenta-se a dedicação de Joaquim Manuel de Macedo aos 


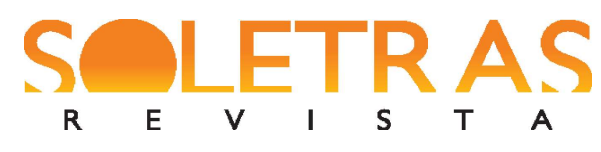

N. 40 - 2020.2 - ANDRÉ CABRAL DE ALMEIDA CARDOSO

escritos políticos que ele passou a publicar em $A$ Nação: "O Sr. Macedo tinha um futuro na literatura, mas a penna do Fantasma Branco e do Cego, graciosa e sentimental, na Nação tornou-se..... não sei, mas não parece uma penna de poeta!" (DRJ, 24/01/1853, p. 1). Para além da exclusão da política - e, portanto, da discussão da realidade social - do domínio da poesia, esse breve comentário alia de forma muito clara o sentimentalismo como valor positivo à produção literária, ecoando, portanto, o tom dos anúncios que analisei na seção anterior. De fato, a sensação de perplexidade do comentarista parece expressar a dificuldade de dar sentido aos escritos de um autor de pretensões literárias em que não se possa perceber a presença do gracioso e do sentimental. Esse tipo de juízo se repete em outros comentários acerca da literatura publicados no Diário. Em uma resenha de Lira dos vinte anos, de Álvares de Azevedo, por exemplo, P. de Calasans celebra o "sentimentalismo doce" que "recende daquela alma apaixonada de mancebo" e conclui que o último poema do livro, "Se eu morresse amanhã", é "um primor melindrosamente sentimental" (DRJ, 06/10/1856, p. 1).

Em outro texto sobre Álvares de Azevedo, desta vez tecendo considerações sobre sua obra como um todo, prefacia-se a tristeza pela morte do poeta com um longo lamento pela extinção dos "sentimentos e as paixões elevadas" no mundo moderno, marcado pela materialidade, à qual se oporia a poesia como "iniciação do pensamento civilisador" (DRJ, 29/02/1856, p. 2). O embate entre o idealismo, ligado ao trabalho nas letras, e as necessidades ditadas pelo culto ao dinheiro é também evocado de forma dramática numa resenha do livro de A. P. Lopes de Mendonça sobre literatura contemporânea (DRJ, 28/12/1855, p. 2-3). Essa oposição marca a tônica de muitos textos publicados no Diário. Em um artigo de opinião em defesa da filosofia popular, assinado por Cousin, ataca-se o materialismo como uma “rehabilitação da carne, e o culto do prazer". Contra ele, coloca-se a necessidade de educar o coração do povo, mas essa educação é em grande parte uma redescoberta, pois, se é preciso tornar acessíveis "os puros mananciais da verdadeira e boa sciencia", na verdade trata-se de permitir que se repouse neles, já que "todos os têm em seus corações". Nesse processo educativo, cumpre expressar as "verdades mais subidas, e mais santas" num "estilo sublime e candido". A razão deve ser cultivada e fortalecida através do emprego de uma "linguagem sensivel mas verdadeira" e "clara": "Esqueçamos a frazeologia peculiar aos systemas e ás escolas; fallemos a linguagem universal e pura da rasão e sentimento" (DRJ, 16/01/1850, p. 1). A retórica sentimental do texto, portanto, aproxima a razão do sentimento, que se tornam em grande medida equivalentes. Desse modo, a educação, voltada para a edificação do espírito, 


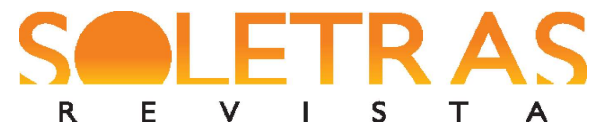

N. 40 - 2020.2 - ANDRÉ CABRAL DE ALMEIDA CARDOSO

torna-se basicamente uma educação sentimental, que nem por isso se afasta da racionalidade. A verdade, por sua vez, não é tanto um objeto de investigação, mas de reconhecimento: ela já está dentro do coração. A linguagem sublime evocada para incuti-la e expressá-la não deve ser ornada e obscura, mas, sim, simples e clara, tal qual aquela buscada na literatura sentimental.

A poesia - e, por extensão, a literatura como um todo - tem um papel fundamental a desempenhar nesse processo educativo, justamente por ser a arte que, ao lidar com a palavra, tem a capacidade de aliar verdade, moral e persuasão. Como explica o texto intitulado "O escriptor", assinado por M. M.: "Um poema, um drama, um romance que pintão vivamente a virtude, modelão o leitor, sem que ele se [sic] sinta, nas personagens virtuosas que obrão; estes [sic] o interessão, e o autor persuadio a moral sem falar dela". A virtude torna-se objeto de interesse ao ser pintada "vivamente", e esse interesse é a base para que o leitor adote uma atitude moral ao imitar as ações das personagens com as quais se identifica através da empatia. A linguagem envolvente da literatura é sedutora e, portanto, convincente. Mais eficaz ou mesmo mais importante do que persuadir através do raciocínio é persuadir através do sentimento: “o homem que resiste as reflecções, que se irrita com as lições dogmaticas, ama o pincel ingenuo e puro que põe em proveito a sensibilidade do coração humano, para lhe mostrar o que o interesse pessoal e feroz repele ordinariamente". A imagem do "pincel ingenuo e puro" evoca mais uma vez a simplicidade da linguagem, ao mesmo tempo em que alia a escrita comovente à pureza da moral, explicitando que esse jogo sedutor não deve ser confundido com o engano ou a falsidade. Ao contrário, ao engajar a sensibilidade e a compaixão do leitor, a literatura realiza uma verdadeira reforma moral, afastando o indivíduo das demandas egoístas de uma sociedade materialista que, esta sim, como dita a tradição sentimental, é pervertida e enganadora. O escritor é um "orador dos desfortunados", e "é preciso que a melancolia, mãi da compaixão, presida ao seu toque entristecido e o torne mais enternecedor" (DRJ, 25/07/54, p. 2). Como já concluía o autor anônimo de um texto intitulado "Poesia", publicado no Diário do Rio de Janeiro em oito de março de 1838: "a poesia é uma cousa util. Companheira da moral, ella a faz penetrar no coração humano por meio do sentimento: e o sentimento para o homem vale mais que todos os raciocinios" (DRJ, 08/03/1838, p. 1).

Se o sentimento vale mais do que os raciocínios, é porque a verdade, que é missão da literatura revelar, já está dada, pois sua natureza é fundamentalmente moral - ou, pelo menos, é desse tipo de verdade que a literatura deve se ocupar. Os textos publicados no Diário do Rio de Janeiro parecem trabalhar com uma noção iluminista, expressa com bastante clareza por 


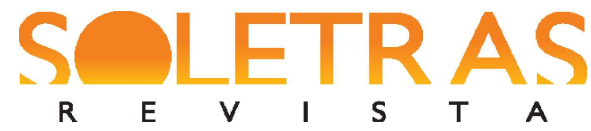

N. 40 - 2020.2 - ANDRÉ CABRAL DE ALMEIDA CARDOSO

Edmund Burke (2015, p. 13) na introdução de seu tratado sobre o belo e o sublime, de que o padrão do gosto e da razão é o mesmo em todos os seres humanos. Desse modo, distingue-se quase que instintivamente o bom do mau assim como se distingue o belo do feio, pois a sensibilidade é uma categoria que atravessa a moral e a estética. A verossimilhança do texto literário se mede menos pela fidelidade aos fatos ou às convenções da realidade do que pela sua capacidade de expressar de forma convincente os sentimentos, medida pelo grau de identificação e comoção que ele pode despertar. Assim, em um texto em que se traça um paralelo entre os romances de Lessage e Walter Scott, o cronista do Diário do Rio de Janeiro avalia positivamente a obra de Scott pela habilidade do autor não de reconstituir fielmente um determinado período histórico mas, sim, de pintar “o coração" (DRJ, 01/07/1855, p. 2). Parecer semelhante surge numa resenha assinada por Lamartine sobre o livro de memórias $A$ família, de Dargaud, em que o escritor francês, depois de expressar sua surpresa diante do fato de um historiador ter composto uma "relíquia de sentimento", acaba por concluir: "E demais não é ainda historia, e a mais interessante das historias, a do lar, da familia e do coração humano?" (DRJ, 14/01/1855, p. 1).

Desse modo, o que se poderia chamar de uma verdade externa, coletiva, ligada aos princípios da sociedade ou ao espírito de um povo, se confunde com a verdade interna do indivíduo. "Na poesia só é grandioso e sublime o que é verdadeiro: a verdade do sentimento tem creado os genios; - estes vivem pela inspirasão, inspirão-se no sentimentalismo de sua alma, cantão ao pulsar cadencioso das fibras do coração" (DRJ, 17/10/1856, p. 1), declara o resenhista de Trovas, coleção de poesias de Laurindo José da Silva Rabello. O impulso do sentimento gera uma cadeia de associações em que a forma (o sublime e o grandioso) encarna perfeitamente o conteúdo (o verdadeiro), sendo que tudo já está no coração do próprio autor, esperando apenas para ser expresso pela poesia e reconhecido pelo leitor através de sua empatia. Cria-se desse modo um efeito de transparência a partir do qual se estabelece a expectativa de uma total identificação, ou mesmo equivalência, entre autor e obra. É desse princípio que parte um comentário retirado de outra resenha de Trovas:

Quem lendo estes versos não avaliará por eles o affecto melindroso da alma do poeta? Em presença do livro do Sr. Laurindo é facil adivinhar as peripecias da sua vida, e ainda mais conhecer as alternativas do seu genio e do seu caracter singular e apprehensivel. (DRJ, 15/04/1856, p. 1). 
Mais do que o espírito do poeta, é possível ler nos seus versos até mesmo a história de sua vida. Essa capacidade da obra de expressar em toda plenitude o caráter do escritor não só é uma das condições para estabelecer a sua verdade, mas também para uma avaliação positiva de suas qualidades estéticas.

As breves biografias publicadas no Diário do Rio de Janeiro oferecem o melhor exemplo dessa identificação entre autor e obra ou, então, da tendência de moldar a vida do autor de modo que ela possa se encaixar numa leitura sentimental de sua obra, criando o mesmo efeito de transparência, de certa forma, a posteriori ${ }^{13}$ Assim, Balzac se torna o personagem de um de seus romances, procurando desesperadamente obter sucesso e ganhar algum dinheiro como tipógrafo e escritor, mas sendo explorado por "editores vampiros" - sem, no entanto, deixar de decifrar "os hieroglyphos os mais obscuros do sentimento" (DRJ, 28/04/1855, p. 1). Mme. de Staël, por sua vez, é apresentada como mulher brilhante, mas recolhida, que ambicionava ser boa e que "aos belos titulos de gloria litteraria, [...] preferia com razão a reputação de uma filha respeitosa e reconhecedora" ( $D R J, 23 / 05 / 1855$, p. 2), tornando-se, portanto, um exemplo de fidelidade filial, como uma típica heroína sentimental. Phillis Wheatley, poetisa negra norteamericana, tal qual uma Ourika reencarnada, conquista o favor de seus senhores com "as amaveis qualidades que a adornavão, a extrema sensibilidade de que era dotada”, obtendo assim sua liberdade a fim de seguir sua carreira literária $(D R J, 17 / 04 / 1841$, p. 1). Finalmente, Kant, aos oito anos, "já manifestava um espirito reflexivo, recto juiso, e grande e nobre sensibilidade"; e, sendo "homem de talento, [...] era ao mesmo tempo homem de bem na rigorosa accepção d'esta palavra; reflectia-se, como em espelho, a sua vida nos seus escriptos" ( $D R J, 27 / 10 / 1840$, p. 1).

O mesmo, infelizmente, não podia ser dito de Rousseau e Lamartine. Apesar de fazerem parte do grupo de autores que pretendem tratar da caridade, esse "sentimento do coração humano", e de Rousseau ser o "primeiro n'esta escola moderna do sentimentalismo philosophico", enquanto Lamartine é o último, ambos falham ao deixar de seguir os preceitos da caridade cristã. Rousseau, "o homem das sensibilidades de coração, que todo ele é finura,

\footnotetext{
${ }^{13}$ Nesse sentido, é significativa a observação de Sandra Vasconcelos (2016, p. 141-149) de que Persuasion acabou se convertendo em um romance sentimental ao ser traduzido para o francês por Isabelle de Montolieu e depois para o português com o título de $A$ família Elliot; ou seja, assim como os autores cujas biografias eram publicadas no Diário do Rio de Janeiro, os próprios romances podiam passar por um processo de "sentimentalização".
} 


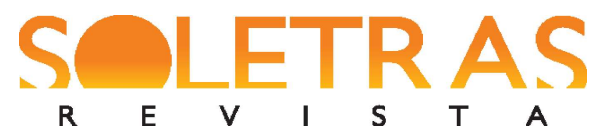

N. 40 - 2020.2 - ANDRÉ CABRAL DE ALMEIDA CARDOSO

pureza de amor e de sentimentos", e "enthusiasta do sublime em materia de sentimentalismo [...], nega com os factos de sua vida a doutrina que escreve: confessa que teve cinco filhos da sua Teresa e mandou-os engeitar todos cinco!...”. Lamartine, "o terno poeta do amor, o homem de coração sensivel e sentimental, o coração mais terno e de sentimentos humanos como se apresenta em toda sua vida", seduz uma jovem italiana com promessas de casamento que não pretende cumprir e acaba levando-a à morte por desilusão (DRJ, 01/10/1851, p. 2). É preciso fazer o reparo de que trata-se aqui de um pequeno texto de caráter religioso, e não de um comentário propriamente literário - a própria redação do jornal faz questão de deixar isso claro ao escrever a palavra "religião" entre parênteses onde deveria constar a assinatura do autor, talvez para preservar a reputação intelectual de dois escritores altamente respeitados na época. No entanto, o texto não deixa de ser ilustrativo da discussão que venho desenvolvendo aqui, pois para além da censura a Rousseau e Lamartine pela sua falta de caridade cristã em seu trato com as mulheres, que é o ponto crucial dessa pequena invectiva, os dois são condenados justamente pela falta de correspondência entre a sua vida e a sua obra. O problema, portanto, não está no sentimentalismo literário ou filosófico desses autores, mas na ausência de transparência que eles apresentam e que é um pressuposto da real efetividade de seus escritos.

Gostaria de encerrar esta discussão com alguns comentários sobre um dos documentos mais célebres da história literária brasileira publicados pelo Diário do Rio de Janeiro. Trata-se da série de cartas escritas por José de Alencar, então redator do jornal, sobre $A$ Confederação dos Tamoios, de Gonçalves de Magalhães, que vieram à luz entre junho e agosto de 1856. Não pretendo fazer uma análise detalhada desses textos, mas apenas traçar um esboço de alguns recursos oriundos da tradição sentimental de que Alencar faz uso em sua crítica e que fazem parte da sua estratégia de persuasão. Ainda que a tônica central de seu discurso seja a preocupação de encontrar o tom certo para compor uma verdadeira epopeia nacional, tópico já bastante discutido na análise da polêmica em torno da Confederação dos Tamoios, ${ }^{14}$ é possível perceber outros focos de interesse que dizem respeito ao próprio fazer poético e que não estão estritamente ligados à questão do nacionalismo.

Num nível ainda bastante superficial, chama atenção o fato de que Alencar frequentemente aponta para as ocasiões em que Gonçalves de Magalhães perdeu a oportunidade de pintar algum quadro de sentimento, como faz logo na primeira carta, ao comentar a cena em

\footnotetext{
${ }^{14}$ Ver, por exemplo, Rocha (1998, p. 45-58).
} 
que Aimbire encontra Pindobuçú e sua filha enterrando um guerreiro morto ( $D R J, 19 / 06 / 1856$, p. 1). Longe de condenar a falta de grandeza épica da cena, o que Alencar parece pedir é um tableau sentimental, um momento da narrativa em que a intensidade do conflito atinge um grau tão elevado que o relato dos eventos se imobiliza para oferecer a imagem do personagem como um corpo sofredor. ${ }^{15} \mathrm{O}$ épico desejado por Alencar, portanto, é já de saída misto, incluindo expectativas típicas da literatura sentimental. Além disso, como a primeira carta também já deixa claro, a própria representação da natureza que Alencar almeja em um épico nacional envolve uma dinâmica ligada às noções de identificação e transparência: o contato com a natureza vicejante do Brasil deveria ter levado o poeta a descrevê-la de forma mais vívida, como se encarnasse em si mesmo e no seu poema aquilo que deveria perceber através de seus sentidos. Assim como a obra de um autor deveria ser a expressão de sua vida, o poema de Magalhães deveria ser uma expressão da natureza brasileira. Além disso, essa natureza "pura" está carregada de uma conotação moral: buscá-la significaria ir ao encontro não só do caráter nacional, mas também da inocência, o que faz com que Alencar, reencenando a oposição sentimental entre natureza e cultura, mostre uma certa hesitação diante do progresso do Brasil, que, se por um lado é necessário ao projeto de construção da nação, também significa a perda da pureza original.

Em um nível mais amplo, já no âmbito das estratégias discursivas, há a opção de Alencar por organizar o texto sob a forma de cartas. Como Paula Frattini (2019, p. 41-45) argumenta, trata-se da elaboração de uma cena e de uma persona autoral com o objetivo de inserir o jovem escritor no mundo das Letras através da polêmica. Ao mesmo tempo, segundo Frattini, Alencar estaria tentando criar um público para a literatura, representado pelo "meu amigo" a que as cartas são endereçadas, que figura como um leitor desejado, mas ainda em grande parte inexistente no contexto brasileiro. Para além disso, porém, é interessante a maneira como Alencar organiza essa cena. A evocação da intimidade através da imagem do amigo cria uma ilusão de espontaneidade e cumplicidade, o que já é um passo importante para angariar a simpatia do leitor, facilitando sua aceitação dos argumentos que serão apresentados, ainda mais se partirmos do princípio de que o leitor objetivo de Alencar estaria treinado para ter expectativas sentimentais, como os textos que analisei até aqui parecem indicar.

\footnotetext{
${ }^{15}$ Para a articulação do tableau no romance sentimental, ver Cohen (1999, p. 65-67). 


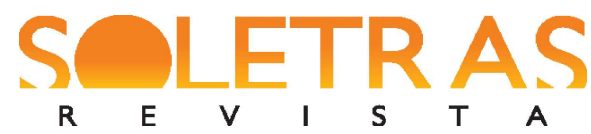

N. 40 - 2020.2 - ANDRÉ CABRAL DE ALMEIDA CARDOSO

Alencar inicia a terceira carta reforçando justamente sua intimidade com seu leitor, através da recordação de momentos que passaram juntos, numa ambientação pacata e doméstica, envoltos na contemplação da poesia e da natureza ( $D R J, 29 / 06 / 1856$, p. 1). A presença da natureza serve mais uma vez como um reforço da identidade nacional, que se revela aqui como parte integrante da cumplicidade sentimental entre os dois amigos, mas também estabelece uma associação com a simplicidade do autor, retomando a despretensão com que este assume o seu papel de crítico na primeira carta, alegando que pretende apenas expor suas impressões sobre o poema de Magalhães, e não realizar uma análise estruturada com rigor $(D R J$, 19/06/1856, p. 1). Esse tom de espontaneidade, marcado também pela suposta ausência de um intervalo entre a leitura do poema e a elaboração da carta (Alencar alega estar escrevendo enquanto continua a leitura de $A$ Confederação dos Tamoios, ou seja, suas impressões seriam imediatas), é uma garantia de sua autenticidade, reproduzindo a dinâmica de uma escrita expressiva que os comentaristas publicados pelo Diário esperavam dos melhores autores Alencar afirma que estaria transmitindo suas "impressões verdadeiras".

O curioso é que o próprio Alencar aponta para a sua inspiração literária ao se desculpar por ter iniciado a carta "á guisa de romance sentimental", pelo qual ele muito se arrepende (DRJ, 29/06/1856, p. 1). Parte desse arrependimento poderia muito bem vir do fato de a referência chamar atenção demais para o caráter ficcional da encenação montada por Alencar. Numa tentativa de mais uma vez reforçar seu tom despojado e espontâneo, Alencar se descreve no final da sétima carta como alguém "no meu retiro, longe do bulicio e do mundo" (DRJ, 12/08/1856, p. 1), o que era uma flagrante invenção, sendo ele o redator-chefe do Diário do Rio de Janeiro naquela época e, portanto, profundamente imerso no "bulício" e no "mundo". Como no caso das biografias de escritores publicadas no jornal, Alencar cria para si mesmo uma verdadeira personagem nos moldes de um romance sentimental. No entanto, mais do que uma estratégia cuidadosamente elaborada para seduzir e convencer o leitor objetivo das cartas, através de uma ilusória transparência do autor, a criação desse personagem está relacionada aos próprios pressupostos críticos adotados pelo autor.

Na sexta carta, Alencar esboça uma distinção entre o crítico e o poeta: ambos lidam com a revelação do belo, mas um faz isso sob a forma do pensamento, enquanto o outro o faz sob a forma do sentimento. O que de início se propõe como uma distinção clara, logo se embaralha, pois o crítico também é caracterizado como um artista ou um poeta, mas um que se debruça sobre a obra já acabada. Ambos têm a missão de cultivar a "flôr mimosa" da arte, mas um 
"planta-a, o outro a colhe; um crea e inspira, o outro sente e comprehende". Nessa superposição de sentir e compreender, já não fica mais óbvio a quem cabe o sentimento e a quem cabe o pensamento. Na verdade, as duas categorias parecem interdependentes, pois o crítico pode julgar "guiado pelo sentimento e por este instincto do belo que Deus deu a todo o homem" (DRJ, 09/08/1856, p. 1). Como Alencar busca demonstrar ao longo de todas as cartas, a crítica não depende da erudição, sendo ela própria um exercício espontâneo, calcado na sensibilidade (ao mesmo tempo em que ele não se furta, supostamente contrariado e apenas forçado pelas circunstâncias da polêmica - parte de seu disfarçado engajamento com o mundo - , fazer várias referências eruditas).

Ao rebater aqueles que defendem A Confederação dos Tamoios argumentando que as faltas apontadas na linguagem do poema eram, na verdade, um efeito da simplicidade que o poeta buscava atingir, Alencar afirma que

[a] simplicidade na arte e na poesia, cujo typo classico encontramos na litteratura grega e em alguns dos seus imitadores, é a naturalidade, é a imitação a mais exacta da vida real, é o sentimento na sua expressão verdadeira sem o realce da fórma e da imaginação. (DRJ, 09/08/1856, p. 1)

Mais uma vez, há um deslizamento da representação da realidade para a expressão do sentimento, novamente associada à verdade. Alencar elabora esse raciocínio na carta publicada no dia 15 de julho de 1856, ao discorrer sobre a natureza da palavra: “[o] sentimento faz d'ella a chave dourada que abre o coração ás suaves emoções do prazer, como o raio do sol que desata o botão de uma flôr cheia de viço e de fragrancia" ( $D R J, 15 / 07 / 1856$, p. 1). Palavra, prazer e sentimento se entrelaçam numa fórmula que coloca o último no centro da fruição estética. No entanto, Alencar vai ainda mais longe:

Eis o que é a palavra, meu amigo: simples e delicada flôr do sentimento, nota palpitante do coração, ella póde elevar-se até o fastígio da grandeza humana, e impor leis ao mundo do alto d'esse throno, que tem por degráo o coração, e por cupula a inteligência. $(D R J, 15 / 07 / 1856$, p. 1) 


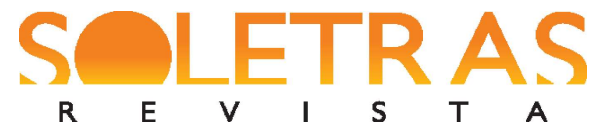

N. 40 - 2020.2 - ANDRÉ CABRAL DE ALMEIDA CARDOSO

A confusão anterior entre o sentir e o pensar agora se esclarece ao tomar a forma de uma hierarquia: o coração é o degrau que se deve galgar para chegar à inteligência; o sentimento, portanto, serve de base para o pensamento. Entretanto, se o pensamento é alçado a uma condição de domínio, necessária para que o escritor realize a sua missão de fomentar o progresso e a civilização, evocada no final de carta, esse domínio não deixa de ser regulado pelo sentimento, já que é a "nota palpitante do coração" que impõe suas leis ao mundo. Se a linguagem do escritor é um "reflexo da razão absoluta" ( $D R J, 15 / 07 / 1856$, p. 1), esta não deixa de ser, de forma alguma, uma expressão do sentimento.

\section{Considerações finais}

Se me alonguei na análise das cartas sobre $A$ Confederação dos Tamoios, é porque elas sintetizam de forma bastante explícita algumas atitudes a respeito da escrita e da leitura que se encontram de forma dispersa nos anúncios e comentários sobre literatura publicados no Diário do Rio de Janeiro entre as décadas de 1830 e 1850. O exame desse material revelou que há um discurso bastante coerente ao longo desse período em torno da produção e recepção de obras literárias, fortemente influenciado pela tradição sentimental. Não quero dizer com isso que se tratava de um discurso unívoco. Havia também, por exemplo, uma certa preocupação realista, que se manifestava com bastante clareza no desejo de reproduzir a cor local ou os costumes e detalhes cotidianos, assim como havia o recurso a categorias caras ao romantismo, como a noção de gênio ou o papel do escritor como arauto da verdade. Mesmo em textos carregados de uma retórica sentimental, algumas dessas noções não deixavam de se fazer presentes, ainda que muitas vezes rearticuladas de formas próprias.

Além de gerar expectativas que guiavam a maneira como as obras eram lidas, esse discurso cristalizava certas concepções a respeito do papel da literatura, dos efeitos que ela poderia produzir e de sua relação com o real. Além disso, ao colocar o sentimento no cerne da experiência estética, os textos que investiguei aqui apontam para uma visão da verdade como algo reconhecível intuitivamente dentro de cada indivíduo. Se a verdade já está dada, bastando que ela seja percebida através da ativação da sensibilidade do leitor no contato com a obra literária, trata-se de uma verdade de natureza essencialmente consensual, pois ela se encontra dentro de todos. O caráter conservador dessa atitude e seus efeitos ideológicos podem ser 


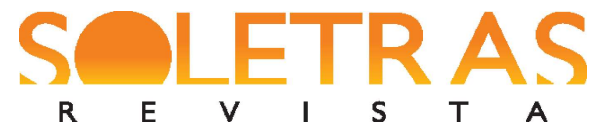

N. 40 - 2020.2 - ANDRÉ CABRAL DE ALMEIDA CARDOSO

notados com facilidade na pressuposição de que essa verdade seria óbvia a todos os "homens sensíveis", que seriam guiados em seu juízo por instintos universais. Para citar um exemplo específico, basta lembrar os anúncios dos livros sobre Luís XVII e a Reforma religiosa, que partem do princípio de que o leitor, guiado pelo seu sentimento, aceitaria tacitamente a denúncia dos males trazidos pela Revolução Francesa e pelo protestantismo. De resto, era comum os comentários críticos publicados no Diário associarem explicitamente o sentimento ao sentimento cristão - ou, mais especificamente, ao sentimento católico.

Nem por isso deixava-se de insistir no ideal do progresso civilizatório. Conforme espero ter demonstrado, a tradição sentimental não era incompatível com o culto à razão, frequentemente evocada nos textos publicados pelo Diário do Rio de Janeiro em conexão com o sentimento. O cultivo da sensibilidade era colocado lado a lado com o cultivo do conhecimento, como componentes de um processo de aperfeiçoamento, em linhas iluministas, tanto do indivíduo quanto do povo. Esse aperfeiçoamento, é claro, estava conectado ao anseio pelo fortalecimento da identidade nacional; no entanto, os textos publicados no Diário do Rio de Janeiro deixam perceber uma preocupação universalista, que muitas vezes sobrepujava o impulso mais estritamente nacionalista. Em primeiro lugar, porque os comentários críticos que surgiam no jornal tinham fontes diversas, sendo muitos deles traduzidos de periódicos estrangeiros, principalmente franceses, ou de origem indeterminada. Isso é uma indicação de que a permanência de uma retórica sentimental surgida em meados do século XVIII não era uma peculiaridade brasileira, nem sinal de atraso, mas se fazia sentir também na França mesmo depois da consolidação do realismo. É preciso lembrar ainda que a noção de sentimento articulada no periódico, apesar de suas amarras ideológicas, tinha por si só um caráter universalista e não estava restrita ao desenvolvimento do espírito nacional. Mesmo nos textos voltados para a produção literária brasileira, o papel civilizatório atribuído à literatura não se limitava ao espaço da nação, mas era visto como parte de um esforço mais amplo, em que a obra do escritor local se articulava ao desenvolvimento da cultura num âmbito mundial.

\section{Referências}

ABREU, Márcia. Conectados pela ficção: circulação e leitura de romances entre a Europa e o Brasil. O Eixo e a Roda, Belo Horizonte, v. 22, n. 1, p. 15-39, 2013. Disponível em: 
<http://www.periodicos.letras.ufmg.br/index.php/o_eixo_ea_roda/article/view/5363/4769>. Acesso em: 19 mai. 2020.

. Problemas de história literária e interpretação de romances. Todas as Letras X, São Paulo, v. 16, n. 2, p. 39-52, nov. 2014. Disponível em: $<$ http://editorarevistas.mackenzie.br/index.php/tl/article/view/7364>. Acesso em: 19 mai. 2020 .

. Apresentação: a ficção como elemento de conexão cultural. In: ABREU, Márcia (org.). Romances em movimento: a circulação transatlântica dos impressos (1789-1914). Campinas: Unicamp, 2016a. p. 15-34.

. Uma comunidade letrada transnacional: reação aos romances na Europa e no Brasil. In: ABREU, Márcia (org.). Romances em movimento: a circulação transatlântica dos impressos (1789-1914). Campinas: Unicamp, 2016b. p. 365-394.

AUGUSTI, Valéria. Trajetórias de consagração: discursos da crítica sobre o Romance no Brasil oitocentista. 2006. 156 f. Tese (Doutorado em Teoria e História Literária) - Instituto de Estudos da Linguagem, Universidade Estadual de Campinas, Campinas, 2006. Disponível em: $<$ http://repositorio.unicamp.br/bitstream/REPOSIP/270042/1/Augusti_Valeria_D.pdf $>$.

Acesso em: 20 mai. 2020.

BARKER-BENFIELD, G. J. The culture of sensibility: sex and society in eighteenth-century Britain. Chicago: University of Chicago Press, 1996.

BOTTING, Fred. Gothic. Londres; Nova York: Routledge, 2005.

BRISSENDEN, R. F. Virtue in distress: studies in the novel of sentiment from Richardson to Sade. Londres: Macmillan, 1974.

BURKE, Edmund. A philosophical inquiry into the origin of our ideas of the sublime and beautiful. Oxford World's Classics. Oxford: Oxford UP, 2015.

COHEN, Margaret. The sentimental education of the novel. Princeton: Princeton University Press, 1999.

DIÁRIO DO RIO DE JANEIRO. Rio de Janeiro: Tipografia do Diário, 1821-1878. 1827-1860. Diário.

FRATTINI, Paula Caldas. Como se dizer autor na cena literária: a cenografia autoral de José de Alencar na polêmica em torno das Cartas sobre A Confederação dos Tamoios. Alea, Rio de Janeiro, vol. 21, n. 3, p. 33-48, set-dez. 2019. Disponível em: $<$ https://revistas.ufrj.br/index.php/alea/article/view/29872>. Acesso em: 31 mai. 2020.

MANÇANO, Regiane. Livros à venda: presença de romances em anúncios de jornais. 2010. 319 f. Dissertação (Mestrado em Teoria e História Literária) - Instituto de Estudos da 
Linguagem, Universidade Estadual de Campinas, Campinas, 2010. Disponível em: $<$ http://repositorio.unicamp.br/jspui/handle/REPOSIP/270049>. Acesso em: 20 mai. 2020.

ROCHA, João Cezar de Castro. Literatura e cordialidade: o público e o privado na cultura brasileira. Rio de Janeiro: EdUERJ, 1998.

VASCONCELOS, Sandra Guardini. Circuitos e travessias: o caso de A família Elliot. In: ABREU, Márcia (org.). Romances em movimento: a circulação transatlântica dos impressos (1789-1914). Campinas: Unicamp, 2016. p. 135-157.

\title{
The truth of the heart: book circulation and sentimental rhetoric in Diário do Rio de Janeiro
}

\begin{abstract}
Taking into consideration the important role of periodicals in the dissemination of literature throughout the $19^{\text {th }}$ century, this paper examines a wide range of texts published in the daily newspaper Diário do Rio de Janeiro between 1830 and 1860 with the aim of tracing the way literary works were presented to the public and discussed during this period, using as reference works by Abreu $(2013 ; 2014$; 2016a; 2016b), Mançano (2010) and Augusti (2006) on the circulation of books in nineteenth-century Brazil. An analysis of the advertisements of books for sale placed in the newspaper, which offer important indications of what was judged to be of interest to the reader at that time, will be followed by an investigation of reviews, author's biographies and opinion pieces also published by the same newspaper, so as to map the way these works were read. Given the strong presence of a sentimental rhetoric in these texts, this paper aims to show how the use of this rhetoric reveals, or even helps shape, certain assumptions regarding the functions of literature, the conditions of its reception and its relation to thought.
\end{abstract}

Keywords: Sentimentalism. Book circulation in the $19^{\text {th }}$ century. Journals. Novel. Criticism.

Recebido em: 31 de maio de 2020 .

Aceito em: 18 de junho de 2020. 